Volume 12

Issue 3

2015

\title{
Using Mindfulness for Increasing Provider Capacity to Support Inner City Survivors of Violence
}

Julianna Andrews, PhD, Stephanie Hartwell, PhD, Carl Fulwiler, MD, PhD, \& Jeroan Allison, MD

$\mathrm{M}$ indfulness is recognized as an evidence-based practice that can improve a person's physical and emotional health and well-being. Practicing mindfulness can help individuals decrease stress, anxiety and emotional attachment to negative events (Kabat-Zinn, 2003). This research project examined the cultural relevance and potential acceptability of mindfulness practices by frontline providers working with a low-income community of color affected by gun homicide.

\section{Research Partners}

The research team was comprised of faculty from the University of Massachusetts Boston, the University of Massachusetts Medical School, and leadership of the Louis D. Brown Peace Institute. The Peace Institute, located in Dorchester, Massachusetts, serves 98\% of the families affected by homicides in urban Massachusetts. The Peace Institute provides crisis response training to ease the psychological stress often experienced by frontline providers.

Additional supports provided by the Peace Institute include: a listserv alerting first responders and providers about recent homicides; monthly providers' breakfasts; and events throughout the year to bring groups together and focus on community development to address violence in society.

The Peace Institute's mission is to serve the community by providing education, tools and supports to ease psychological distress brought about by homicide. The Peace Institute is exploring incorporating mindfulness techniques to expand coping options for family members and front-line service providers dealing with gun-related homicides.

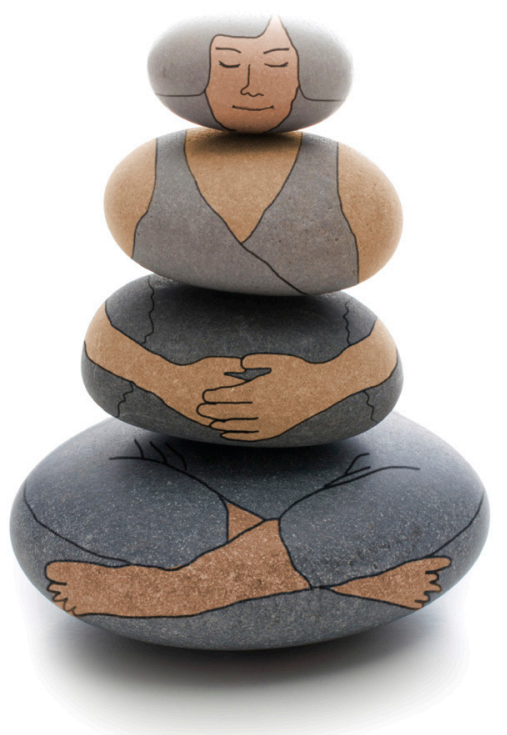

\section{Study Participants and Design}

In the Fall of 2014, the Peace Institute staff hosted a series of mindfulness trainings targeting three distinct groups:

1. family members of homicide victims;

2. Peace Institute staff; and,

3. front-line service providers.

All family member participants were mothers who had experienced loss to violence ranging from as recent as 2 weeks to up to 20 years; all identified as non-white. Front-line service providers were counselors who work with families of homicide victims from a variety of agencies in Boston. Working with staff, clients, and a certified mindfulness practitioner, the team restructured the standardized mindfulness training curriculum to accommodate the target audiences. Mindfulness trainings for each group were delivered over three sessions of 2 hours each. At the conclusion of the trainings, the research team conducted focus groups and surveys with each of three groups to assess the impact of the training 
and to learn about how to further adapt mindfulness to better assist and meet the needs of high-risk victims of gun violence, front-line service providers, and first responders.

\section{Findings to Date}

\section{Family Members of Homicide Victims:}

Mothers were emotionally open with their grief and described the difficulty they face daily with tasks such as "breathing," "silencing their minds," and their inability to relax. The trainings helped them learn mindful breathing techniques and strategies to channel their grief in peaceful instead of violent ways. They also enjoyed the exercises introduced during the trainings that included mindful eating and yoga. Some mothers noted:

It helped me to just be there with other mothers with the same type of trauma, it was peaceful. I loved Bonita's voice and the bells. The entire experience was rewarding and helpful.

During the past two weeks all I have told myself is to breathe. Even out loud when I needed to though people looked at me like I was crazy, but I was able to do it.

Family members were positive about the mindfulness training, and were open to committing to further training.

\section{Front-line Providers:}

Half of the front-line providers reported that they used mindfulness techniques for "self-care." Self-care strategies included meditation, yoga, mindful eating, and working out at the gym. All front-line providers recognized the benefit of practicing mindfulness, and identified the importance of mindfulness in their daily lives. As they described:

It brings a person into a different stage of calm, takes them out of trauma mode and lets them decompress.

It helps gain control over actions and is helpful in focusing.
While the majority of front-line providers stated they had an interest in mindfulness, they were hesitant to commit to taking a longer training due to time constraints and already feeling overwhelmed with their work.

\section{Peace Institute Staff:}

The Peace Institute staff were very positive about the mindfulness trainings. One suggestion included hosting a mindfulness mini-course as part of their Survivor Leadership Academy, the goal of which is to help survivors try new methods to manage their grief and healing. Peace Institute staff suggested that the curriculum could be altered to include survivors and front-line providers teaching mindfulness to others in a "train the trainer" model. Staff noted that mindfulness is a good alternative to clinical care, which can often re-traumatize survivors if not conducted using traumainformed techniques. The Peace Institute staff were also concerned that front-line providers often do not prioritize their own self-care. Peace Institute staff noted:

I learned to take care of me, to be still, to not take stuff home, unplug, when we unplug we are not in control - this is an awareness providers need to have. If you find this hard to do, you cannot expect clients to do it.

I'm traumatized from doing this work, taking half the meeting to do mindfulness is hard. My self-care is being with everyone to talk. I want to socialize, that is how it seems like an inconvenience. Only doing it for an hour then back to this intense work. We need to remind them [front-line provider] this is what you are telling your client to do.

\section{Future Directions}

Although the positive response of family members indicated no major cultural barriers, next steps include revising the content of the mindfulness training to increase cultural relevance based on their feedback, and infusing mindfulness into the Peace Institute's Survivor Leadership Academy and front-line provider's breakfast.

Research Team: Stephanie Hartwell, PhD; Carl Fulwiler, MD, PhD, Jeroan Allison, MD; Julianna Andrews, $\mathrm{PhD}$ Candidate UMass Boston; Tina Chery, Executive Director of the Louis D Brown Peace Institute; Rachel Rodriques, Director of Training and Education at the Louis D Brown Peace Institute. Funder: Creative Economies Grant, UMass President's Office University of Massachusetts. Time Frame: 2014-2015; Contact: Stephanie.Hartwell@umb.edu 


\section{References}

Kabat-Zinn, J. (2003). Mindfulness-based interventions in context: past, present, and future. Clinical Psychology: Science and Practice, $10(2), 144-156$.

Using Mindfulness for Increasing Provider Capacity - Julianna Andrews, PhD, Stephanie Hartwell, PhD, Carl Fulwiler, MD, PhD, \& Jeroan Allison, MD 